\title{
One-year Evaluation after Placement of Ceramo-Metal Crown Restoration, on Endodontically Treated Maxillary First Premolar (In-Vivo Case Report)
}

\author{
Author \\ Saleh A. Alfaleh \\ General Dental Practitioner
}

\begin{abstract}
A 41-years old male patient came to our dental clinics complaining of pain related to upper left area. After full evaluation and investigations, patient needs long treatment plan. Treatment was done within 7 months as full mouth treatment. In this report I am evaluate the ceramo-metal crown restoration after root canal treatment of maxillary first premolar. After one year evaluation, the tooth did not shows any sign or symptoms of failure.

Keywords: Ceramometal, root-canal-treatment, premolar, Endodontics, Prosthodontics.
\end{abstract}

\section{Introduction}

In a traditional full ceramo-metal tooth restoration, the strength is provided by the metal substructure, and a porcelain veneer provides esthetics. full ceramo-metal tooth restoration are used to restore badly broken down teeth to protect remaining tooth structure. It may also be responsible for maintaining occlusion and providing aesthetics. Margins are unacceptable, if the gap between margins of the crown and tooth structure is greater than $50 \mathrm{um}$ allowing insertion of the tip of the explorer inside. Marginal gap between the crown and the tooth may lead to micro leakage and secondary caries. Secondary caries beneath crown margins is considered the most frequent reason for failure of crowns and fixed prosthodontic treatment.

Advantages of full ceramo-metal tooth restoration is the underlying metal fused with the porcelain provides stability and strength to the crown. also it has great aesthetic appeal and is most commonly preferred as it gives the restored tooth a natural look. They have a very high rate of success in the long run.

Disadvantages of this type of restoration is the cosmetic appearance of these restoration is commendable but they are less appealing than other types. They make the gums more vulnerable to gingival inflammation as compared to porcelain fused to gold and porcelain crowns. Restoring tooth with these crowns requires a large part of the tooth structure to be removed. Porcelain from the crown can easily break or chip off. The teeth which bite against these crowns bet worn out in the long run. Increased cost becomes a major drawback when precious metals are fused.

Full ceramo-metal tooth restoration are nothing but a hybrid between porcelain and metal crowns. Initially a metal shell is prepared which can fit perfectly over the concerned tooth. Then a porcelain veneer is fused on the metal shell which gives the crown a natural looking appearance. 
The best part of these crowns is the stability and strength which is unmatched to any other restorations available today. Properly constructed and seated full ceramo-metal tooth restoration provide optimal strength and longevity. An anatomical framework design is crucial to provide proper support and maintain the appropriate thickness for the veneering porcelain.

The following criteria are critical to proper fabrication:

1. The coefficients of thermal expansion of the porcelain and alloy must be closely matched to achieve a strong bond; otherwise, adhesive failure (eg, delamination or fracture) may occur.

2. Proper casting temperature and timing are needed to prevent overheating or miscasting. Excess gas in the alloy can cause small surface pits and bubbles in the veneering porcelain.

3. A smooth metal surface must be achieved via finishing procedures to strengthen the bond with the veneering porcelain.

4. It is important to avoid sharp angles or pits on the veneering surface, which can lead to cracking due to internal stress.

5. Heat treatment is necessary for degassing and to create an oxide layer, which promotes a chemical bond between the alloy and porcelain.

6. The use of an opaque layer as the first porcelain coat is crucial for three reasons: (1) to ensure a strong bond at the interface of the opaque porcelain and alloy, (2) to mask the metal color, and (3) to provide a base color for the targeted shade. When a satisfactory opaque layer has been baked, the dentin (body), enamel, and incisal (translucent) porcelain layers can be applied to achieve the desired appearance. The fabrication of full ceramo-metal tooth restoration involves many steps; therefore, errors may occur. Nevertheless, more than 50 years of research, development, and clinical experiences show that PFM crowns in the posterior region maintain a high survival rate $(95 \%)$ with well-established strength and reliability.

\section{Case Report}

A 41-years old Saudi fireman complaining of pain related to upper left area. After full examination and investigations, he needs multi dental speciality treatment. The case was discussed with our consultants (OMFS, Periodontics, Prosthedontics, Endodontics and Restorative Dentistry). Here I am discussing and evaluating the full ceramo-metal tooth restoration on endodontically treated maxillary first premolar.

Pre-operative Examination and diagnosis is cavitated distal caries clinically (Fig. 1 and 2),

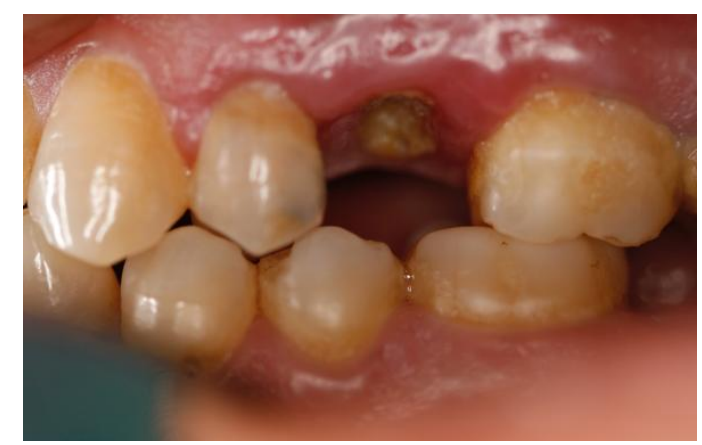

Fig. 1 Pre-operative intraoral lateral view

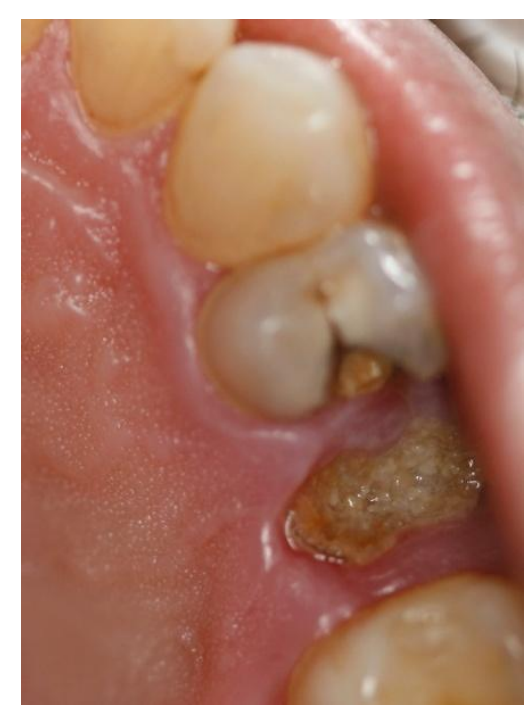

Fig. 2 Pre-operative intraoral occlusal view peri-apical radiograph shows extended large caries to pulp champer with apical radiolucency. (Table-1) shows the Endodontics finding and diagnosis for this tooth. 


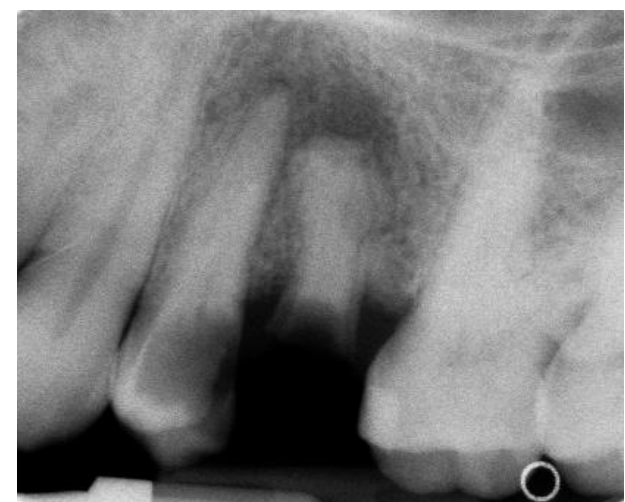

Fig. 3 Pre-operative intraoral periapical radiograph

Table-1 Endodontics findings and Diagnosis

\begin{tabular}{|l|l|}
\hline Test & Result \\
\hline Cold Test & Negative \\
\hline Percussion Test & Negative \\
\hline Palpation & Negative \\
\hline Pulpal Tissue Diagnosis & Necrotic Pulp \\
\hline Apical Tissue Diagnosis & $\begin{array}{l}\text { Asymptomatic Apical } \\
\text { Periodontitis }\end{array}$ \\
\hline
\end{tabular}

\section{Treatment Plan}

According to our finding and investigation, this tooth must be treated endodontically then crowned. After presenting this case with all treatment possibilities to the patient we decide to do root canal treatment for this tooth after extraction of adjacent tooth (maxillary second premolar), then restore maxillary first premolar with fiber-post and core and ceramo-metal crown. After that, dental implant will be placed to restore maxillary second premolar after evaluation of osteoplasty.

\section{Clinical Procedure}

\section{Preliminary Phase}

Caries excavation and pulp extirpation, Calcium Hydroxide was paced intracanal as an intracanal medicament. Cotton pellet and glass ionomer restoration as an intermediate restoration material.

\section{Endodontics Phase}

Removing of intermediate restoration material and intracanal medicament, root canal treatment was started by hand filing instrumentation by step-back technique.
Master apical file was size 25 for both canal (buccal and palatal), working length was $21 \mathrm{~mm}$ in buccal canal and $20.5 \mathrm{~mm}$ for palatal canal. Irrigation by $5.25 \%$ Sodium Hypochloride and normal saline after each file, Ethylen Diamine Tetra Acetic Acid (EDTA) irrigation after last file.

Obturation was done with Gutta-Percha cones according to master apical file by lateral condensation technique.

Fiber-Post space preparation was done.

\section{Prosthetic Phase}

Fiber-post placement, Core build-up, crown preparation with shoulder finish line. Impression was taken by Poly Vinyl Siloxane (light and regular body), provisional crown restoration.

After receiving the crown from dental laboratory, crown was checked on the cast and inside patient mouth. Then cemented by Poly Carboxylate cement. Occlusion was checked.

(fig. 4 and 5) shows the post-operative photograph immediately after placement. While (fig.6) shows the post-operative peri-apical intraoral radiograph.

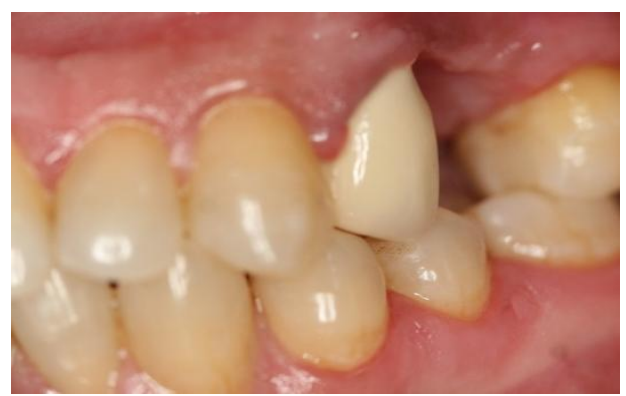

Fig. 4 Intraoral lateral view

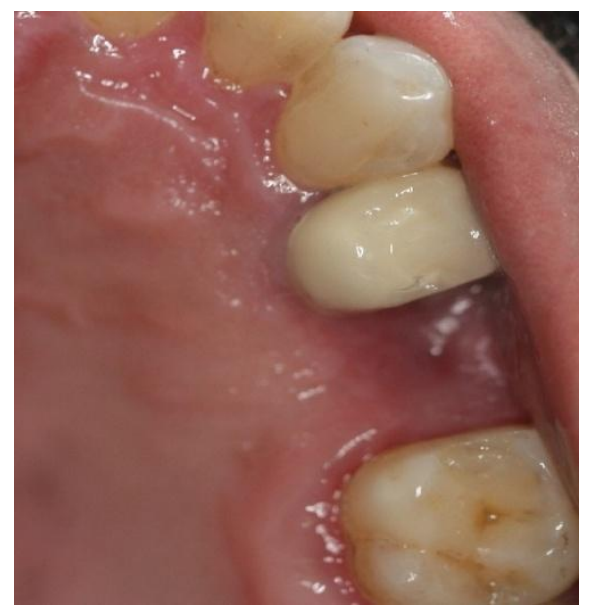

Fig. 5 Intraoral occlusal view 


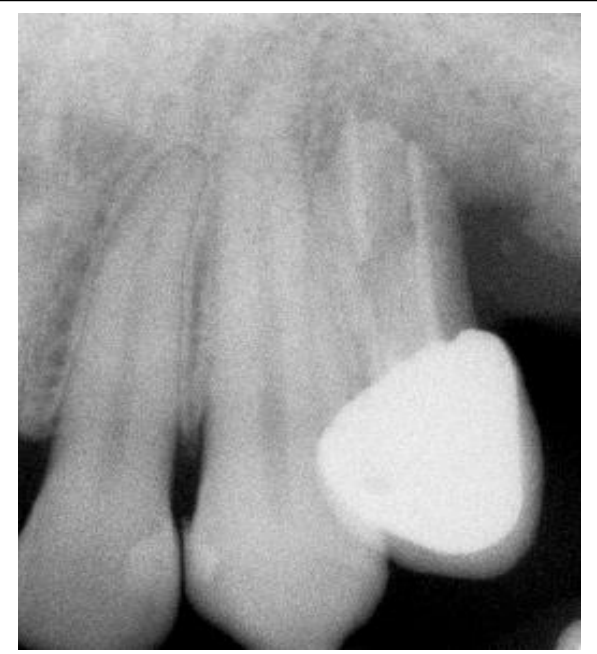

Fig. 6 Intraoral peri-apical radiograph

\section{Follow-Up and Re-evaluation}

Patient was recalled for follow-up and re-evaluation after 2 months of placement and 1 year. (fig. 7 and 8)

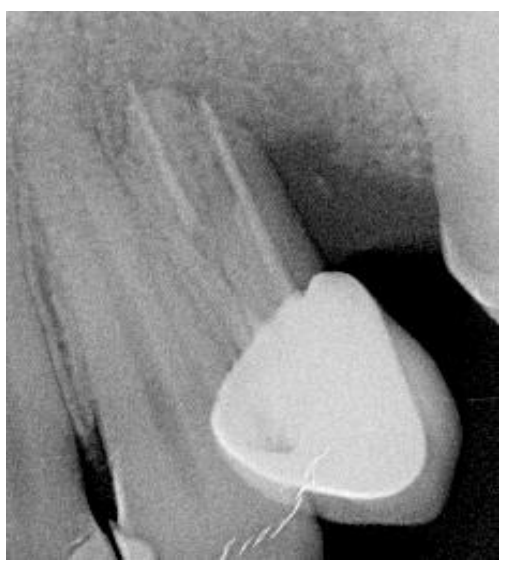

Fig. 7 2-months post-operative intraoral peri-apical radiograph

2-months follow-up radiograph shows sign of healing by decreasing in size of apical radiolucency.

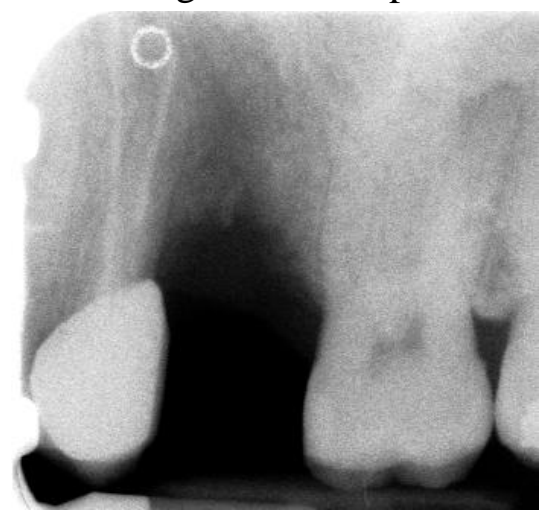

Fig. 8 1-year post-operative intraoral peri-apical radiograph

\section{References}

1. Rosenstiel SF, Land MF, Fujimoto J. Contemporary Fixed Prosth- odontics, ed 4. St Louis: Mosby, 2006.

2. Yamamoto M. Metal-Ceramics: Principle and Methods of Ma- koto Yamamoto. Chicago: Quintessence, 1985.

3. Ban K. Q\&A: Ceramometal science. In: Dental Technology Li- brary, ed 1. Tokyo: Ishiyaku, 1989:2-20.

4. Gungor MA, Artunc C, Dundar M. Sevenyear clinical fol- low-up study of Probond ceramic crowns. Quintessence Int2007; 38:456-463.

5. Vigolo P, Mutinelli S. Evaluation of zirconium-oxide-based ce- ramic single-unit posterior xed dental prostheses (FDPs) generated with two CAD/CAM systems compared to porcelain- fused-to-metal single-unit posterior FDPs: A 5-year clinical prospective study. J Prosthodont 2012; 21:265-269.

6. Blatz MB, Bergler M, Ozer F, Holst S, Phark HJ, Chiche GJ. Bond strength of different veneering ceramics to zirconia and their susceptibility to thermocycling. Am J Dent 2010;23:213-216.

7. Michalakis KX, Stratos A, Hirayama H, Kang K, Touloumi F, Oishi Y. Fracture resistance of metal ceramic restorations with two different margin designs after exposure to masticatory simulation. J Prosthet Dent 2009; 102:172-8.

8. Reitemeier B, Hansel K, Walter MH, Kastner C, Toutenburg H. Effect of posterior crown margin placement on gingival health. J Prosthet Dent 2002; 87:167-72.

9. Reeves WG. Restorative margin placement and periodontal health. J Prosthet Dent 1991; 66:733-6.

10. Christensen GJ. Frequently encountered errors in tooth preparations for crowns. $J \mathrm{Am}$ Dent Assoc 2007; 138:1373-5. 
11. Ramfjord SP. Periodontal aspects of restorative dentistry. J Oral Rehabil1974; 1:107-26.

12. Orkin DA, Reddy J, Bradshow D. The relationship of the position of crown margins to gingival health. J Prosthet Dent 1987; 57: 421-4.

13. Smukler H, Chaibi M. Periodontal and dental considerations in clinical crown extension: a rational basis for treatment. Int J Periodontics Restorative Dent 1997; 17:464-77. 